\title{
SEISMIC PERFORMANCE OF A MASONRY BUILDING ISOLATED WITH LOW-COST RUBBER ISOLATORS
}

\author{
AHMAD B. HABIEB ${ }^{1}$, GABRIELE MILANI $^{1}$, TAVIO $^{2}$ \& FEDERICO MILANI ${ }^{3}$ \\ ${ }^{1}$ Politecnico di Milano, Italy \\ ${ }^{2}$ Institut Teknologi Sepuluh Nopember, Indonesia \\ ${ }^{3}$ Chem.Co Consultant, Italy
}

\begin{abstract}
New residential buildings in developing countries often have inadequate seismic protection, particularly for masonry. Such material is widely preferred because the cost and application are relatively cheap. To decrease the vulnerability, an interesting option is represented by seismic isolation, but the cost should remain relatively low, and this is the reason why rubber isolation with few pads remains the most suitable technical solution to adopt. In this study, we deal with a newly conceived low-cost seismic isolation system for masonry buildings relying on elastomeric bearings. The elastomeric isolator here proposed consists of few layers of rubber pads and fiber lamina, making it cheaper compared to the conventional isolators. A detailed 3D finite element $(\mathrm{FE})$ analysis to predict the behavior of the lowcost rubber isolator undergoing moderate deformations is carried out. A Yeoh hyperelasticity model with coefficients estimated through available experimental data is assumed for rubber pads. Having so derived the shear behavior, such an isolation system is implemented at a structural level into a two story masonry house prototype, identifying the 3D model with a damped nonlinear spring model, so making the FE analysis computationally inexpensive. For masonry, a concrete damage plasticity (CDP) model available in the commercial FE code Abaqus is adopted. A nonlinear static-pushover analysis is conducted to assess the performance of the isolated building. To simulate a realistic condition under a seismic event, ground motion data is applied to observe the dynamic behavior of the building by monitoring the damage level of masonry. Through a-posterior estimation, it is also possible to monitor the deformation of the isolators during the seismic excitation, to determine whether the isolator is capable of resisting shear deformations in different angles. According to the results obtained, quite good isolation is obtained with the system proposed, with immediate applicability at a structural level. Keywords: masonry housing, low-cost seismic isolation, rubber isolators, advanced FE modelling, nonlinear static pushover analyses, dynamic analyses.
\end{abstract}

\section{INTRODUCTION}

Seismic isolation is an effective technical solution to reduce the vulnerability of new and existing structures. Indeed, it can mitigate the negative impact of an earthquake, because it shifts the period of the structure in that range of the spectrum where the spectral acceleration is low.

Masonry is a quite common building material in developing countries [1], because it is relatively cheap and even unspecialized masons can be utilized for the construction. It is therefore the preferred material in developing countries. It typically consists of clay bricks bonded by mortar joints. Without resisting moment frames, masonry can withstand seismic loads only thanks to the in-plane shear and flexural strength of piers and spandrels, but unfortunately, conventional brick masonry exhibits poor tensile strength, so its capacity to carry horizontal loads is considerably lower than standard reinforced concrete and steel frames. In many cases of earthquake events in high seismicity regions, such as for instance Indonesia, low-class housings experienced severe damage and many casualties [2] occurred. This fact justifies the importance of conceiving a new low-cost seismic isolation system for low-class housing, generally applicable in all those developing countries subjected to strong earthquakes. 


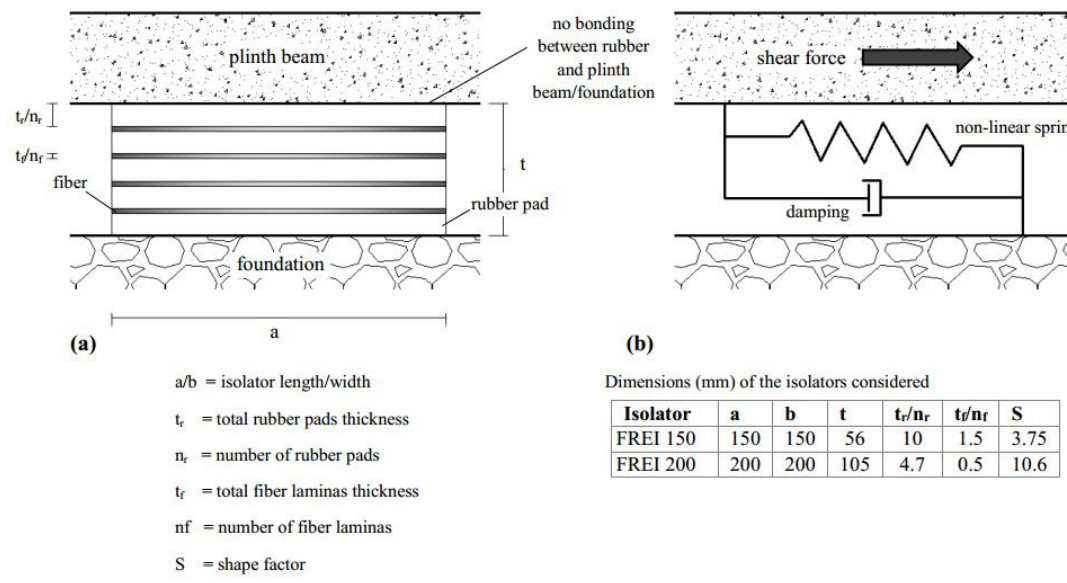

Figure 1: (a) Geometry of the elastomeric isolator; and (b) The representative damped spring model.

A well known and relatively cheap seismic isolation device is the so-called elastomeric isolator. Typically, it is constituted by several layers of rubber (pads) and steel or fiber laminas interposed by two continuous pads, having the role of limiting vertical deformability [3]. At the same time, such isolator exhibits good deformation capacity in the horizontal direction when subjected to a seismic load, thanks to the small shear stiffness of the pads. This system can isolate the energy transmission of the earthquake from the foundation to the upperstructure. Some recent researches in the field employed glass fiber laminas to make the cost of the isolator even cheaper $[4,5]$, sometimes in combination with used recycled rubber from tires or industrial waste [6,7], to further drop down costs.

The objective of this paper is to analyze the seismic performance of a newly conceived low-cost Fiber Reinforced Elastomeric Isolator (FREI) when applied to low-rise masonry buildings. When compared with standard FREIs available in the literature, see for instance [8], here we consider a brand new FREI exhibiting smaller dimensions and much fewer pads. After having numerically deduced the shear behavior of the isolator by means of a detailed 3D FE discretization where a Yeoh hyperelasticity model [9] with coefficients estimated through available experimental data is assumed for rubber pads, we model the isolator embedded into an entire masonry building prototype as a damped non-linear spring, Fig. 1(b). Such classic identification method allows for straightforward computations in large scale structural FE analyses, with an obvious advantage against models involving a detailed 3D FE discretization of each single device. Previous research recommends this way of modeling [10] rubber pads. Fiber laminas are assumed behaving elastically, again in agreement with consolidated literature in the field, see for instance [5]. For masonry, a concrete damage plasticity CDP model available in the commercial FE code Abaqus is adopted. CDP is particularly indicated in the analysis of materials with different strength in tension and compression because it assumes distinct damage parameters. Although CDP [11-13] is originally conceived for isotropic fragile materials (typically concrete), it can be adapted to masonry, because orthotropy ratio in the brickwork is moderate (around 1.2) under biaxial stress states in the compression-compression region [14-16]. Obviously, orthotropy is lost in CDP, but it is commonly accepted the use of isotropic models after an adaptation of the parameters to fit an average behavior between vertical and horizontal values. 
It is worth also mentioning that an elastomeric isolator should be typically characterized using several DOFs (e.g. three DOFS for the horizontal and vertical directions, two for bending and torsion). At least in principle, a complex masonry building may generate torsion on the foundation elements, but this situation is true globally, whereas the local behavior of a single device, which can be regarded as a material point, excludes meaningful torsional effects. On the other hand, a rotational motion which in a moment resisting frame can be considerable is unlike because a masonry structure generally distributes uniformly the horizontal and vertical loads. In this work, we also consider the critical horizontal displacement that the isolator can resist under vertical load due to the weight of two-story masonry housing. Since the height of the building is relatively low, the variation of the vertical compression during static and dynamic analyses is not taken into account.

The prototype studied is a two-story masonry house with a thinner wall and smaller FREIs compared to the prototype constructed in Tawang, India, which is the first masonry building in India isolated with unbonded fiber reinforced elastomeric isolators (U-FREIs). The building model with and without isolation are analyzed in Abaqus through nonlinear static pushover and dynamic analyses. Through those analyses, we present some damage states of the building during excitation as recommended by. The damage states are determined by the level of inter-story drift. In the Abaqus simulation, we can also observe the damage of masonry elements in which the tensile strength limit is exceeded. Results highlight how the proposed isolation system may considerably improve the seismic performance of the masonry building, competing with more expensive FREIs already available. Through a-posteriori estimation, the shear deformation of the isolators in different angles is also monitored, to determine whether their practical applicability is possible finding, in any case, positive results.

\section{FINITE ELEMENT MODEL}

\subsection{Numerical model of fiber reinforced elastomeric isolator}

Hyperelasticity is an important issue in this study to define the behavior of the elastomeric isolator. Some researchers proposed models of hyperelasticity based on the strain energy function. In this study, properties of the rubber are assumed following Yeoh hyperelastic model due to its simplicity of computation.

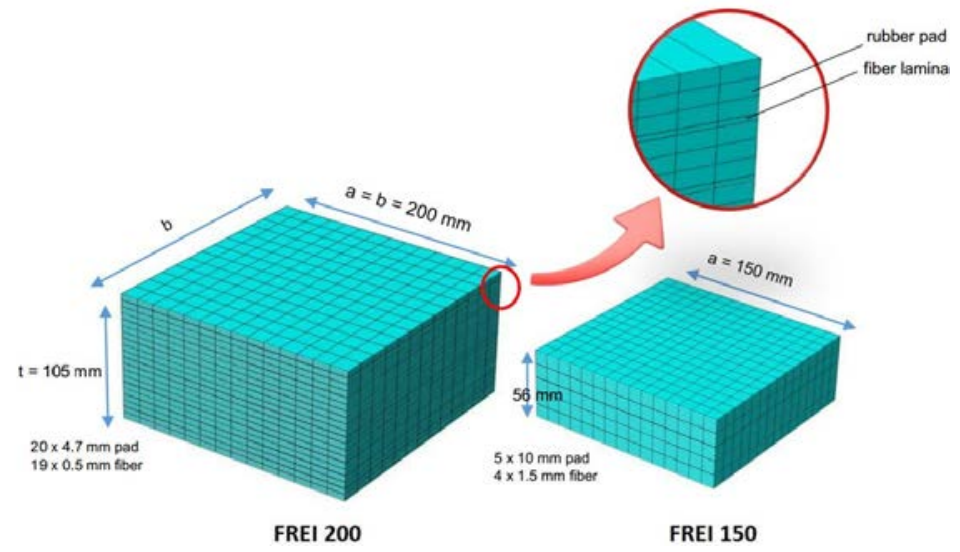

Figure 2: Size comparison of isolators considered and meshing of FE model. 

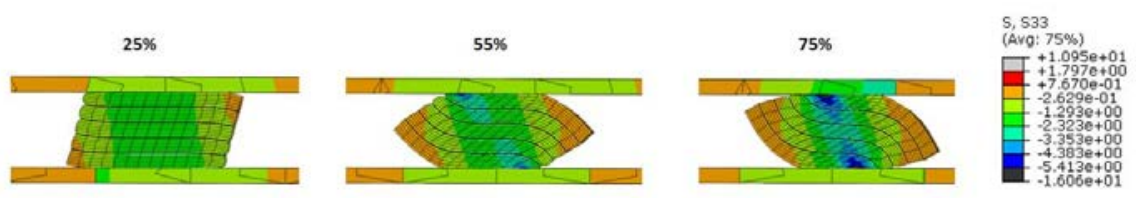

Figure 3: Deformation and stress S33 of U-FREI 150 undergoing horizontal displacement and constant vertical pressure, $2.1 \mathrm{MPa}$.

In the present study, we estimate these coefficients by referring to a previous paper [17]. That paper evaluates the Yeoh coefficients of rubber materials with different hardness. In this work, we use the same rubber material examined in an earlier study on isolators [8], with a Shore A hardness equal to 40. Elastomeric isolators discussed in this work use fibers as reinforcement to improve the vertical stiffness. It has been shown indeed, that fibers can reduce the cost of the isolator when compared with steel lamina [7, 18]. In this numerical simulation, we consider that the fiber behaves as an elastic material with Young modulus $\mathrm{E}=40000 \mathrm{MPa}$ and Poisson's ratio $=0.25$.

Fig. 1(a) introduces the dimensions of three different isolators we propose. The U-FREI 200 is an isolator tested at McMaster University (Hamilton, Canada) [8]. We consider it as the reference sample. Its size is $200 \mathrm{~mm}$ both in length and width. Another specimen is the isolator we propose, with much smaller dimensions than the previous one. U-FREI 150 has only five pads of rubber with $10 \mathrm{~mm}$ of thickness, while U-FREI 200 has 20 pads, $4.7 \mathrm{~mm}$ of thickness. Fig. 2 shows the geometry of the isolators and the mesh used for the FE models. Rubber pads and FRP laminas are modeled with 28756 and 10225 eight nodes parallelepiped solid elements for U-FREI 200 and U-FREI 150, respectively. We consider the U-FREI 150 as the isolation devices for two-story masonry building since in our previous work, U-FREI 100 (the length of its side is $100 \mathrm{~mm}$ ) work efficiently in the case of one-story housing.

We perform pure shear analyses under geometric and material non-linear hypotheses, applying a constant vertical load on the upper surface of the isolator, to observe its behavior at increasing values of horizontal displacement. The isolators are used in an unbonded application, see Fig. 3, where the upper and lower edges do not exhibit perfect bonding with the supports, but a frictional limited strength. Under moderate shear forces, such frictional limited strength allows the isolator to roll over and facilitates larger deformations. Comparing to a bonded application, peak tensile stresses on rubber decrease and it can eliminate the need of thick steel support.

In the present simulation, we consider that a single isolator is subjected to a vertical load of 5.4 tons $(2.1 \mathrm{MPa})$. This is because the masonry building prototype analyzed later has a total weight of 220 tons, and 46 isolators on the foundation level are utilized. To realistically reproduce experimental results, it is needed to generate the hysteresis behavior of the isolators. Two of the authors of this paper proposed a simplified hysteresis behavior of rubber to be used in FE model by mixing elastoplastic concepts and hyperelastic properties [19]. In the present paper, we adopt a similar procedure. First, we generate a nonlinear behavior of the FE model only with a nonlinear elastic model for rubber pads, i.e., without different loadingunloading paths, see Fig. 4(b). The dashed line represents the shear behavior obtained by the FE analysis of a U-FREI 200. Having at disposal such displacement-load curve, we input it as the properties of a nonlinear spring at a structural level for $\mathrm{X}$ and $\mathrm{Y}$ axis. To generate the hysteresis behavior, a damping coefficient to the s pring is a lso a pplied. In this $\mathrm{c}$ ase, a value of $10 \%$ damping turns out to be suitable for a reasonable fitting of experimental data 

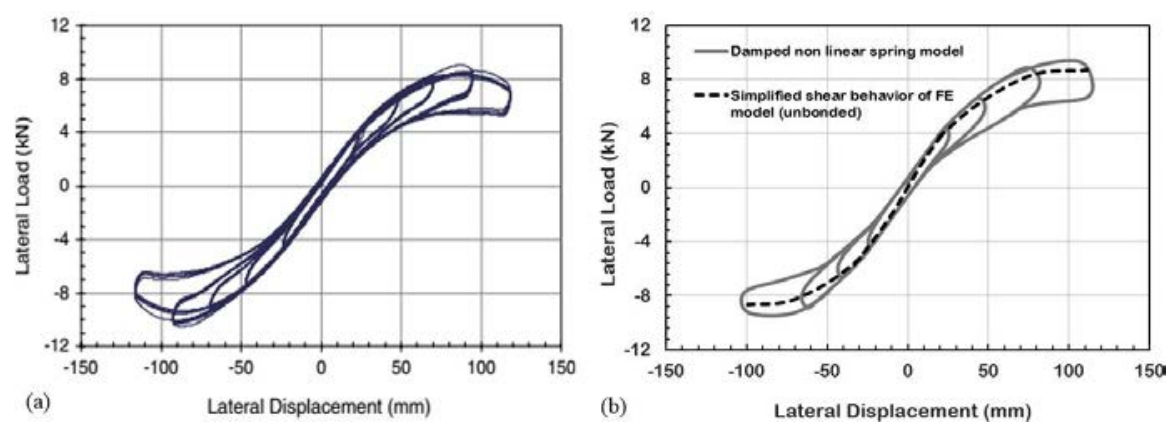

Figure 4: (a) Experimental shear behavior of U-FREI 200; (b) Shear behavior of U-FREI 200 by FE model and representative damped-spring model.

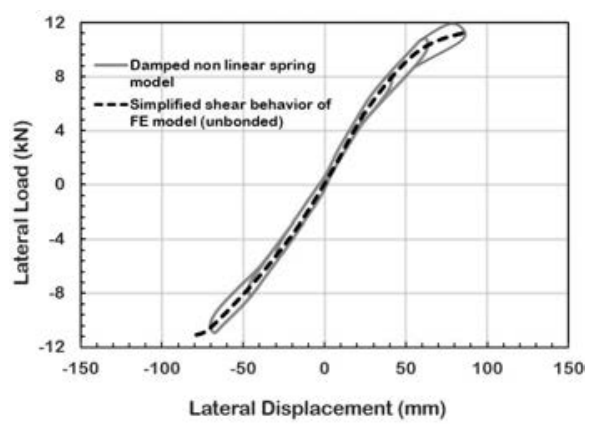

Figure 5: Shear behavior of FE unbonded model and representative damped-spring model for U-FREI 150.

(Fig. 4(a)). Consistently, we adopt this damping coefficient also for another FE model. For U-FREI 150, Fig. 5 shows the shear behavior and the corresponding model adopted for the identified non-linear spring to use at a structural level.

Such identification procedure satisfies the simplified model introduced in Fig. 1. Modeling a spring instead of a real 3D isolator makes the computation more efficient. Furthermore, we are capable of simulating a masonry structure with a realistic representation of the isolation system.

\subsection{FE model of an isolated masonry house prototype}

A model of a two-story masonry house with openings and concrete diaphragms in foundation and roof level is considered. The dimension of the building are the following: thickness of the walls $300 \mathrm{~mm}$, each room has $4 \times 4 \mathrm{~m}$ plan dimensions, and height of each floor $3 \mathrm{~m}$, see Fig. 6. Also, the weight of the roof is $50 \mathrm{~kg} / \mathrm{m}^{2}$. To prevent the flexural damage of the walls, some rigid beams on top of the windows and the door are presented.

In modeling masonry, we consider it as an isotropic material. Even this is a simplification, it is commonly accepted in engineering practice [20,21], also because commercial FE codes have rarely at disposal orthotropic damaging materials in their standard packages. As far as the non-linear behavior is considered, we adopt a concrete damage plasticity model (CDP). This model is available in the standard package of Abaqus FE software and compatible with 
Table 1: Values of the mechanical parameters adopted for FE Model.

\begin{tabular}{ccccc}
\hline Dilatation angle & Eccentricity & $\sigma_{\mathrm{b} 0} / \sigma_{\mathrm{c} 0}$ & $\mathrm{~K}_{\mathrm{c}}$ & Viscosity \\
\hline 10 & 0.1 & 1.16 & 0.667 & 0.0001 \\
\hline
\end{tabular}

the nonlinear behavior of brittle or quasi-brittle materials such as concrete and therefore masonry.

The CDP model requires data on the non-linear behavior in uniaxial tension and compression. For this study, the simplified axial stress-strain relationships shown in Fig. 7 are utilized. The tensile damage determines mainly the overall state of damage of the masonry prototype since mortar tensile strength is considerably low. The stress-strain relation in tension exhibits a peak strength of $f_{r m t}=0.15 \mathrm{MPa}$ for the unreinforced masonry. This value corresponds to the tensile strength of mortar and is taken in agreements with experimental data. Then micro-cracks start to propagate within the material, leading to a macroscopic softening. In compression (Fig. 7), the response is linear up to the yield stress $f_{\mathrm{y}}=1.8 \mathrm{MPa}$, followed by a crushing stress $f_{\mathrm{u}}=2.4 \mathrm{MPa}$ and linear softening branch. Then we input other parameters of CDP obtained from a previous research [20] as seen in Table 1.

An interesting issue that cannot be taken into account in a macroscopic FE approach is the technological detail of the connection of the isolator with the structure. To facilitate the application of a base isolator, rigid beams at the base of the walls should be disposed. This configuration lets the elastomeric isolator optimally work between the foundation and the upper structure (Fig. 6).

In this FE analysis, the number of isolators involved is 46 with equally stepped distance $(1.3 \mathrm{~m})$, see Fig. 6. Damped nonlinear springs identified with the procedure previously discussed are interposed between the foundation and rigid beams. The house is subjected to pushover forces and a real accelerogram of L'Aquila earthquake, with peak ground accelerations, $\mathrm{PGA}=0.6 \mathrm{~g}$. One of the main aims is to examine the performance of the

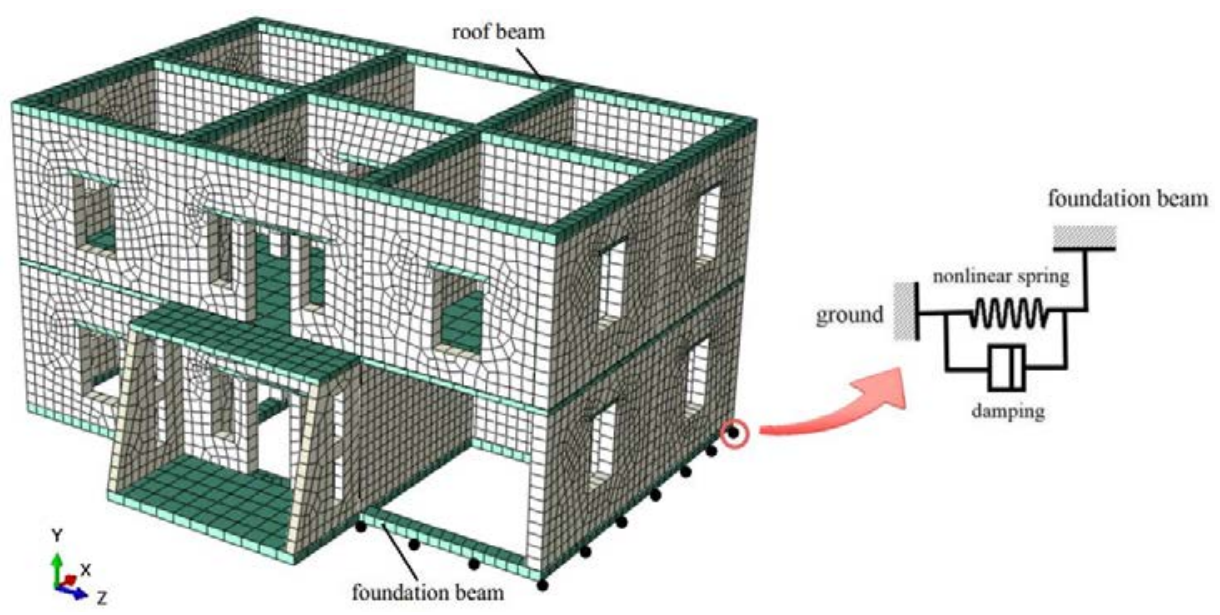

Figure 6: Mesh of two-story masonry house with isolation system and numerical model of an isolator. 

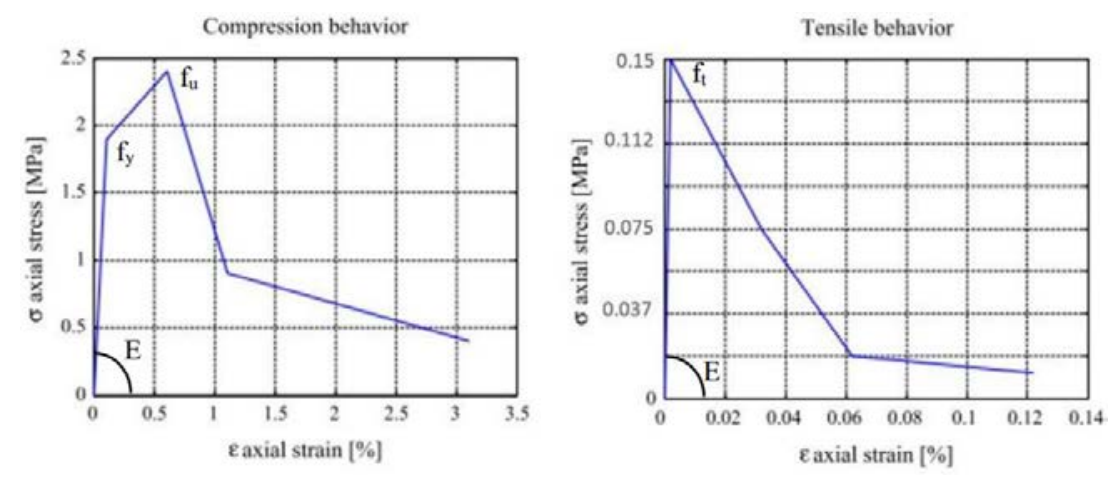

Figure 7: Simplified nonlinear behavior in uniaxial tension and compression.

isolator regarding isolation capability and reduction of damage on the upper-structure, through a pushover and dynamic analysis.

\section{NON-LINEAR STATIC PUSHOVER ANALYSIS}

In pushover analysis, the first mode of vibrations of the building is considered. The pushover force is distributed corresponding to the weight of each floor. In this paper, we discuss only the pushover force through the weaker axis, X-direction. Fig. 8 shows the static pushover curve of the building with and without isolation, describing the relationship between base shear and top displacement. In the non-isolated curve, we notice a softening effect of masonry material during unloading phase.

To classify the level of damages exhibited by the masonry building during pushover excitation, damage state limit recommended by Calvi [22] is employed. DS 2, DS 3, and DS 4 represent moderate, extensive, and collapse damage, respectively. Such classification corresponds to the magnitude of inter-storey drift observed during the test.

For building without isolation (Fig. 8), moderate, extensive, and collapse damage occur in sequence from 2.8 till $27 \mathrm{~mm}$ of top displacement. Meanwhile, in the second model, the isolation can delay the moderate and extensive damage at 69 and $95 \mathrm{~mm}$ of top displacement, respectively. We introduce DS 5 as the damage of the isolator device, when its critical

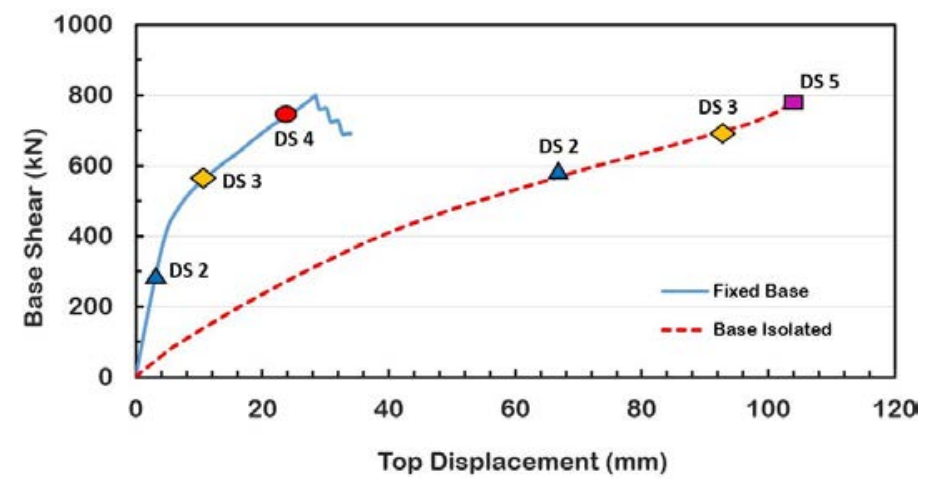

Figure 8: Pushover curve of two-story masonry building with and without isolation. 

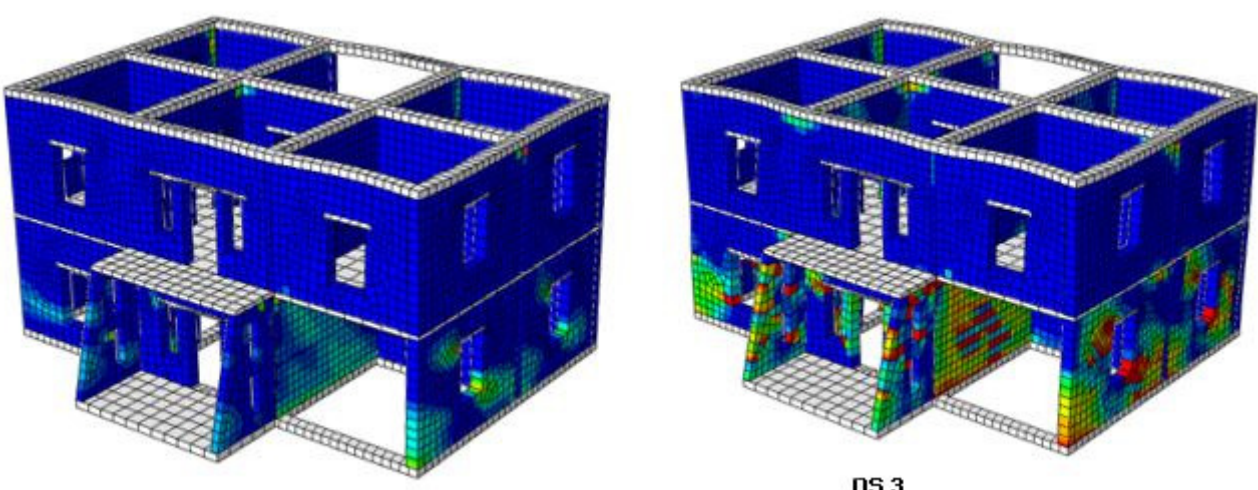

DS 3

DS 2

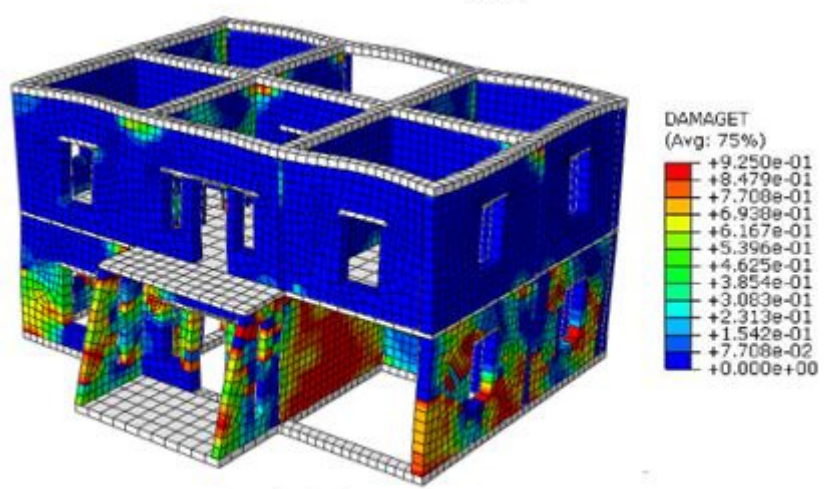

DS 4

Figure 9: Level of tensile damage in masonry housing during pushover analysis.

horizontal displacement under corresponding vertical load is exceeded, about $85 \mathrm{~mm}$ for UFREI 150. Also, we assume that no more damage can be recorded after a failure of the isolator devices. Thus, no collapse (DS 4) of masonry is noticed in the isolated model. Those curves reveal that the isolation system proposed may mitigate very well the seismic vulnerability of masonry housing in terms of damage state delay.

The software used in this study is capable of showing in post processing the damage level of the elements. When the level of damage reaches 0.925 , the material undergoes 0.003 of tensile strain, which corresponds to mortar total cracking. Fig. 9 illustrates tensile damages experienced by the masonry building during pushover test, related to the level of damage states. It seems that in this pushover analysis, for two-story housing, the tensile damages mainly develop in the first floor, since the distribution of force is more concentrated at the top of the first story.

In masonry structures under shear or seismic excitation, damage in compression does not play an important role in determining the failure behavior. And this is the reason why such issue is not discussed in the present paper.

\section{NON-LINEAR DYNAMIC ANALYSIS}

After the application of the seismic load within a non-linear dynamic analysis scheme, it is possible to appreciate the structural behavior of masonry with and without isolation. 


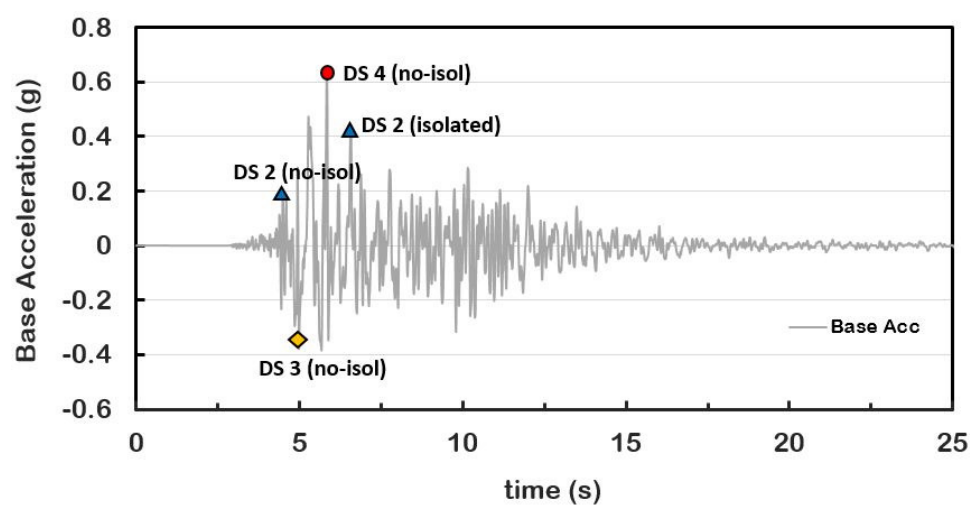

Figure 10: Accelerogram of L'Aquila earthquake and damage states of masonry housing without and with elastomeric isolators.

Fig. 10 shows the damage development of the building subjected to accelerogram L'Aquila $(\mathrm{PGA}=0.6 \mathrm{~g}$ ). Without seismic protection (fixed base), a moderate damage (DS 2) is noticed when $t=4 \mathrm{~s}$, followed by extensive damage (DS 3) at $t=5 \mathrm{~s}$, and collapse (DS 4) at the peak of accelerogram, $t=5.8 \mathrm{~s}$. On the contrary, the utilization of the isolators helps in a considerable mitigation of house damages. We do not notice any extensive and collapse damage until the end of the test. Only a moderate damage occurs at $t=6.5 \mathrm{~s}$, a few moments after peak ground acceleration.

Fig. 11 presents the corresponding tensile damages of the masonry in several damage states during the seismic excitation. In the isolated model, at the end of the test, the volume of damaged masonry elements is much less than that of the house without isolation. Unlike in static pushover analysis (Fig. 9) where the tensile damages are concentrated on the first floor, the tensile damages in the dynamic model are spread at the first and second floor.

Finally, it is interesting to discuss the horizontal deformation of the isolators. In this 3D idealization, we are capable of observing the shear deformation of the isolator in some different angles, which affect the critical shear deformation of the U-FREI. Such maximum deformation is useful to evaluate whether the device is applicable in practice. After having the horizontal displacement of the building through dynamic analysis, we return to analyze the detailed 3D model of U-FREI 150 undergoing inclined shear deformations. Figs 12 and 13 show the shear behavior of the U-FREI 150 under predefined vertical pressure $(2.1 \mathrm{MPa})$ in varied displacement angles. $U_{t}$ is the maximum deformation observed in the model during the seismic motion, and $U_{\text {crit }}$ is the critical point of horizontal deformation. We can conclude that having more displacement angle, the critical point is slightly decreased. In the case of U-FREI 150, the critical point is seemly determined by a full-contact deformation of the rubber pad, presenting a jumping stiffness on the shear behavior curve. It also indicates that the isolation system satisfies the limit of shear displacement for all inclination levels during L'Aquila seismic case.

\section{CONCLUSIONS}

We carried out detailed 3D FE analyses on a newly conceived low-cost fiber reinforced elastomeric isolator in an unbonded application. Such type of isolator may facilitate a moderate horizontal deformation during a seismic motion. The isolator proposed has considerably smaller dimensions comparing to the conventional ones. 

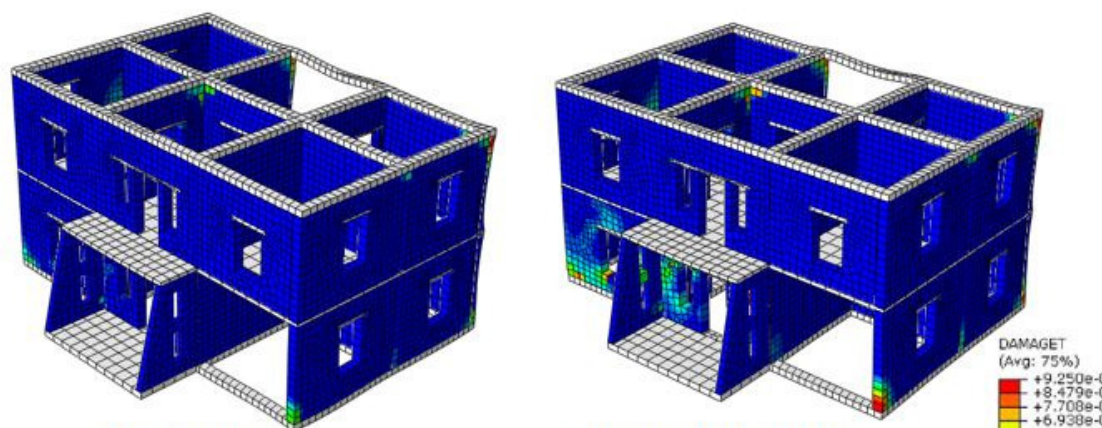

DS 2 (both models)

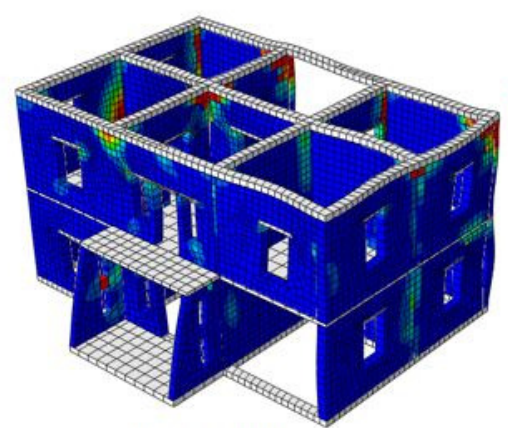

DS 3 (non isolated)

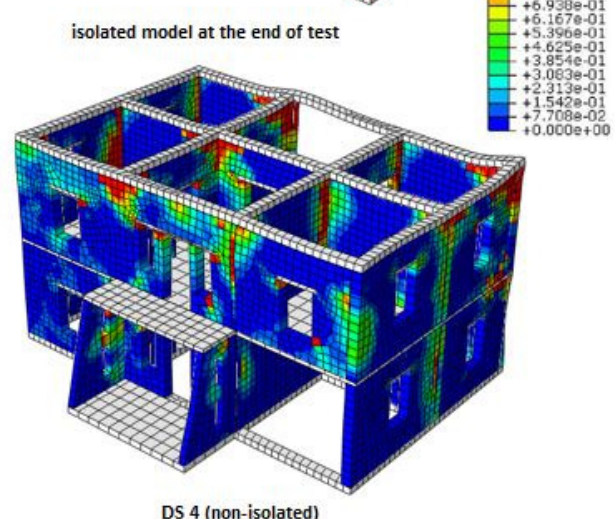

Figure 11: Tensile damage of masonry during L'Aquila earthquake at corresponding damage states.

To simplify the numerical analysis, the isolator is modeled at a structural level as a damped nonlinear spring, to apply at the base of the upper-structure. This simplified method seems to work reasonably well and leads to faster computations rather than modeling the real 3D geometry of the isolators into FEs. The benchmark structure is a two-story masonry house, which is analyzed through a nonlinear static pushover and dynamic analyses, with and without isolation. The capability of the rubber isolator is evaluated by monitoring its shear deformation in different angles of horizontal loads. The results reveal that the isolation system
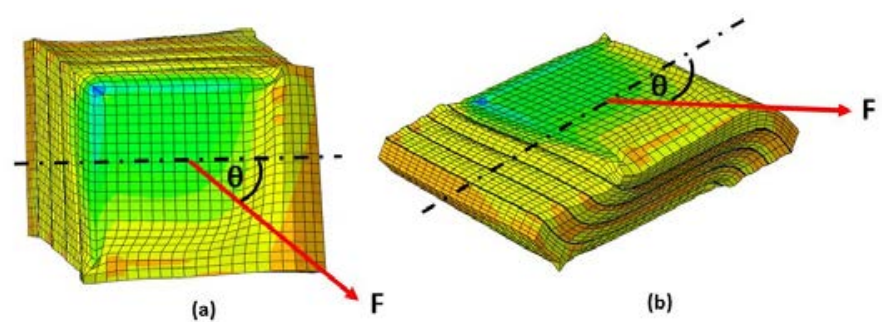

(b)

Figure 12: A possible inclined shear deformation exhibited by the U-FREI 150 during seismic motion. (a) Top; and (b) Side view. 

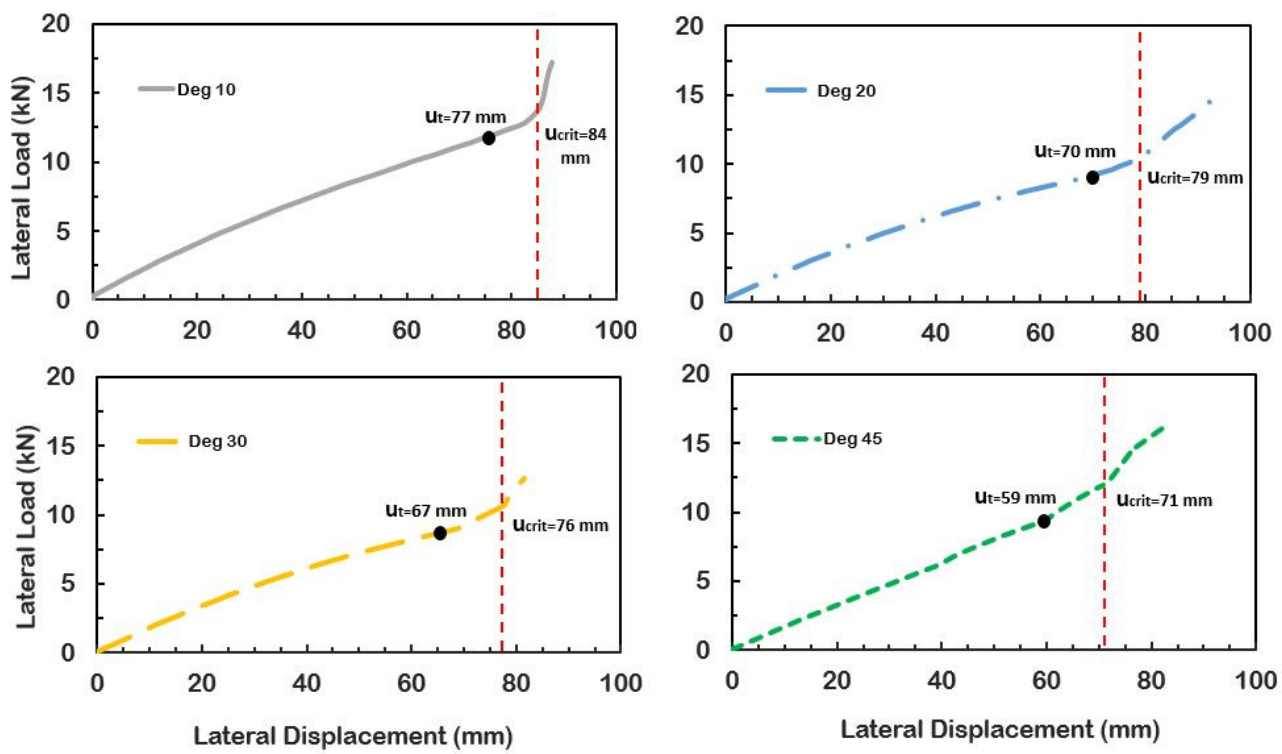

Figure 13: Behaviors of U-FREI 150 in different angles of shear deformation due to L'Aquila earthquake.

proposed can improve the seismic performance of the masonry building effectively, with an excellent applicability of the low-cost rubber isolator.

\section{ACKNOWLEDGEMENT}

The authors would like to acknowledge the financial support from LPDP Scholarship, Finance Ministry of Indonesian Republic for sponsoring Mr. Ahmad B. Habieb to study at Politecnico di Milano, Italy.

\section{REFERENCES}

[1] Nanda, R.P., Shrikhande, M. \& Agarwal, P., Low-cost base-isolation system for seismic protection of rural buildings. Practice Periodical on Structural Design and Construction, 21(1), p. 04015001, 2015.

[2] Boen, T., Yogya Earthquake 27 May 2006: Structural Damage Report. EERI, 2006.

[3] Kelly, J.M., Earthquake-Resistant Design with Rubber, Springer, 1993.

[4] Das, A., Deb, S.K. \& Dutta, A., Shake table testing of un-reinforced brick masonry building test model isolated by U-FREI. Earthquake Engineering \& Structural Dynamics, 45(2), pp. 253-272, 2016.

[5] Van Engelen, N.C., Osgooei, P.M., Tait, M.J. \& Konstantinidis, D., Experimental and finite element study on the compression properties of modified rectangular fiberreinforced elastomeric isolators (MR-FREIS). Engineering Structures, 74, pp. 52-64, 2014.

[6] Turer, A. \& Özden, B., Seismic base isolation using low-cost scrap tire pads (stp). Materials and Structures, 41(5), pp. 891-908, 2008.

[7] Spizzuoco, M., Calabrese, A. \& Serino, G., Innovative low-cost recycled rubberfiber reinforced isolator: experimental tests and finite element analyses. Engineering Structures, 76, pp. 99-111, 2014. 
[8] Toopchi-Nezhad, H., Tait, M.J. \& Drysdale, R.G., Testing and modeling of square carbon fiber-reinforced elastomeric seismic isolators. Structural Control and Health Monitoring, 15(6), pp. 876-900, 2008.

[9] Shahzad, M., Kamran, A., Siddiqui, M.Z. \& Farhan, M., Mechanical characterization and FE modelling of a hyperelastic material. Materials Research, 18(5), pp. 918-924, 2015.

[10] Kumar, M., Whittaker, A.S. \& Constantinou, M.C., An advanced numerical model of elastomeric seismic isolation bearings. Earthquake Engineering \& Structural Dynamics, 43(13), pp. 1955-1974, 2014.

[11] Acito, M., Bocciarelli, M., Chesi, C. \& Milani, G., Collapse of the clock tower in finale Emilia after the may 2012 Emilia Romagna earthquake sequence: Numerical insight. Engineering Structures, 72, pp. 70-91, 2014.

[12] Valente, M. \& Milani, G., Non-linear dynamic and static analyses on eight historical masonry towers in the north-east of Italy. Engineering Structures, 114, pp. 241-270, 2016.

[13] Castellazzi, G., DAltri, A.M., de Miranda, S. \& Ubertini, F., An innovative numerical modeling strategy for the structural analysis of historical monumental buildings. Engineering Structures, 132, pp. 229-248, 2017.

[14] Page, A., The biaxial compressive strength of brick masonry. Proc. Instn Civ. Engrs, 71(2), pp. 893-906, 1981.

[15] Milani, G., Lourenço, P.B. \& Tralli, A., Homogenised limit analysis of masonry walls, part I: Failure surfaces. Computers \& Structures, 84(3), pp. 166-180, 2006.

[16] Milani, G. \& Venturini, G., Safety assessment of four masonry churches by a plate and shell fe nonlinear approach. Journal of Performance of Constructed Facilities, 27(1), pp. 27-42, 2011.

[17] Jerrams, S., Kaya, M. \& Soon, K., The effects of strain rate and hardness on the material constants of nitrile rubbers. Materials \& design, 19(4), pp. 157-167, 1998.

[18] Calabrese, A., Spizzuoco, M., Serino, G., Della Corte, G. \& Maddaloni, G., Shaking table investigation of a novel, low-cost, base isolation technology using recycled rubber. Structural Control and Health Monitoring, 22(1), pp. 107-122, 2015.

[19] Milani, G. \& Milani, F., Stretch-stress behavior of elastomeric seismic isolators with different rubber materials: numerical insight. Journal of Engineering Mechanics, 138(5), pp. 416-429, 2011.

[20] Choudhury, T., Milani, G. \& Kaushik, H.B., Comprehensive numerical approaches for the design and safety assessment of masonry buildings retrofitted with steel bands in developing countries: The case of India. Construction and Building Materials, 85, pp. 227-246, 2015.

[21] Tiberti, S., Acito, M. \& Milani, G., Comprehensive fe numerical insight into finale Emilia castle behavior under 2012 Emilia Romagna seismic sequence: damage causes and seismic vulnerability mitigation hypothesis. Engineering Structures, 117, pp. 397$421,2016$.

[22] Calvi, G.M., A displacement-based approach for vulnerability evaluation of classes of buildings. Journal of Earthquake Engineering, 3(03), pp. 411-438, 1999. 